\title{
ANALISIS CITRA MEREK, POSITIONING PRODUK DAN LIFESTYLE TERHADAP KEPUTUSAN PEMBELIAN PADA TOKO BAJU THE EXECUTIVE DI SOLO PARAGON MALL
}

\author{
Fitrysia Hanggraini, Ida Aryati DPW, Rochmi Widayanti \\ Program Studi Manajemen Fakultas Ekonomi Universitas Islam Batik Surakarta \\ fitrysiabayuaji@gmail.com
}

\begin{abstract}
ABSTRAK : The goal of this study is the quality of brand image, positioning products, and lifestyle locations for clolithing store the executive di solo paragon mall. The population in this study were consumers who bought products from The Executive at Solo Paragon Mall. The sampling technique uses accidental sampling, ie sampling is done by giving a questionnaire to get a sample based on the users of the product from The Executive who were met at the time of the research, which was taken from the research area. The data analysis method used in this study is descriptive statistics all analysis and regression analysis. Descriptive statistics of all analyzes, all interpretations, data obtained, and results of data processing carried out, carried out with explanations, explanations, and explanations. Regression analysis includes validity and reliability testing, classic assumption test, multiple regression analysis, determination test, $\mathrm{t}$ test, and 1 test. The results of the $\mathrm{F}$ test show that brand image, product positioning, and lifestyle have a simultaneous effect on purchasing decisions at the executive clothing store at the paragon mall solo. Brand image has a positive effect on purchasing decisions at the executive clothing store at Paragon Mall. Positioning products have a positive effect on purchasing decisions at the executive clothing store in Paragon. Lifestyle has a positive effect on purchasing decisions at the executive clothing store in Paragon. The results of the coefficient of determination of the results of analysis of multiple linear calculations can be seen that the number of adjustments R2 obtained is 0,632 or $63,2 \%$. This shows that brand image, product positioning, and lifestyle have an influence on purchasing decisions in the executive store at the paragon mall solo.
\end{abstract}

Keyword : Brand Image, Positioning Product, Lifestyle

\section{PENDAHULUAN}

Perkembangan fashion di indonesia kini semakin berkembang mengikuti arus modernisasi. Perkembangan ini menjadikan masyarakat sebagai masyarakat yang selektif didalam menentukan gaya hidupnya. Gaya hidup sangat erat hubunganya dengan fashion, karena adanya fashionakan menunjang penampilan seseorang agar lebih menarik dan menjadi trend center di kalangan masyarakat (Sisilia dkk, 2015).

Karena saat ini para pengusaha garmen perlu menggunakan keahlian para desainer untuk selalu up to date agar tidak ketinggalan fashion yang sedang menjadi trend, dalam dunia mode pakaian, merek merupakan sebuah nilai tambah sehingga memicu munculnya persaingan antar merek (Ujang, 2015). Faktor pertama yang mempengaruhi keputusan pembelian konsumen yaitu citra merek. Menurut Nurhayati (2017) citra merek merupakan serangkaian kepercayaan tentang suatu merk setelah melalui tahap dalam proses persepsi, lalu dilanjutkan dengan keterlibatkan konsumen saat melakukan pembelian. faktor kedua yang mempengaruhi keputusan pembelian yaitu positioning produk. Rahmawati \& Arsyanto (2018) berpendapat bahwa, positioning 
berkaitan dengan menciptakan brand perception pada benak konsumen dengan memperoleh gambaran merek yang berbeda dibandingkan dengan produk pesaingnya dan memenuhi kebutuhan konsumen atau ekspetasi konsumen. Faktor ketiga yang mempengaruhi keputusan pembelian adalah gaya hidup. Meilani (2017) berpendapat bahwa, gaya hidup merupakan suatu titik tempat pertemuan antara kebutuhan ekspresi diri dan harapan kelompok terhadap seseorang untuk bertindak, yang tertuang dalam norma norma kepantasan. The Executive merupakan produk dengan berbagai keunggulan seperti citra merek yang sudah dkenal disemua kalangan. Fenomena brand dapat dilihat dalam bisnis fashion, semakin banyaknya minat beli fashion seperti saat ini mendorong konsumen melakukan identifikasi pengambilan keputusan. Saat menentukan brand untuk kebutuhan serta keinginan, perusahan terus berkompetensi mempertahankan strategi guna menciptakan inovasi baru dalam pemenuhan kebutuhan konsumen. Berdasarkan kesimpulan diatas maka perumusani masalahnya adalahi sebagai berikut 1. Apakah ada pengaruh secara simultan citra merek, positioning produk, dan lifestyle terhadap keputusan pembelian pada toko baju The Executive di solo paragon mall? 2. Apakah ada pengaruh citra merek terhadap keputusan pembelian pada toko baju The Executive di solo paragon mall ? 3. Apakah ada pengaruh positioning produk terhadap keputusan pembelian pada toko baju The Executive di solo paragon mall ? 4. Apakah ada pengaruh lifestyle terhadap keputusan pembelian pada toko baju The Executive di solo paragon mall ?

\section{LANDASAN TEORI}

Malik (2018), berpendapat bahwa keputusan pembelian merupakan salah satu tindakan yang dilakukan oleh konsumen untuk melakukan pembelian suatu produk yang mereka inginkan. Citra merek merupakan representasi dari keseluruhan persepsi terhadap merek dan dibentuk dari informasi dan pengalaman masa lalu terhadap merek itu.Menurut Wirakusuma (2018) mendefinisikan positioning produk adalah tindakan perusahaan untuk merancang produk dan bauran pemasaran agar dapat tercipta kesan tertentu dibenak konsumen dengan demikian konsumen dapat memahami apa yang dilakukan perusahaan dengan para pesaingnya.

Meilani (2017) berpendapat bahwa lifestyle merupakan suatu titik tempat pertemuan antara kebutuhan ekspresi diri dan harapan kelompok terhadap suatu untuk bertindak, yang tertuang dalam norma-norma kepantasan.

\section{METODELOGI PENELITIAN}

Jenis penelitian ini menggunakan kuantitatif deskriptif.Populasi dalam penelitian ini adalah konsumen yang membeli produk dari The Executive di Solo paragon mall berjumlah tidak terhingga dan tidak diketahui jumlahnya.Jumlah Sampel pada penelitian ini adalah 100 responden. Tehnik pengambilan sampel, penulis memilih menggunkan tehnik non-probabilty sampling. Data diperoleh dengan menyebar kuesioner. Waktu penelitian dilaksanakan kurang lebih selama 6 bulan dari bulan januari 2019 sampai bulan juni 2019, Teknik analisis data yang digunakan adalah analisis regresi linier berganda, uji t, uji $\mathrm{F}$ dan koefisien determinasi. 


\section{ANALISIS DATA DAN PEMBAHASAN}

\section{Analisis Data}

\section{1) Uji Asumsi Klasik}

a. Uji Normalitas

hasil pengujian Kolmogrov-Smirnov-Test menunjukan bahwa nilai Asym. Sig. (2-tailed) lebih besar dari $0,05(0,441)>(0,05)$. Hal ini menunjukan bahwa persamaan regresi untuk model dalam penelitian ini memiliki sebaran data yang normal.

b. Uji multikolinearitas

Uji Multikolineritas bertujuan untuk menguji apakah model regresi ditemukan adanya korelasi antar variabel bebas.Metode regresi yang baik tidak terjadi korelasi antar variabel independen.Untuk menguji ada atau tidaknya multikolineritas yaitu dengan menggunakan nilaiVariance Inflation

\begin{tabular}{|c|c|c|c|c|}
\hline \multirow[b]{2}{*}{ Variabel } & \multicolumn{4}{|c|}{$\begin{array}{c}\text { Tabel IV. } 6 \\
\text { Hasil Uji Multikolineritas }\end{array}$} \\
\hline & $\begin{array}{l}\text { Tolera } \\
\text { nce }\end{array}$ & VIF & Keterangan & \\
\hline $\begin{array}{l}\text { Citra } \\
\text { Merek }\end{array}$ & 0,449 & 2,227 & $\begin{array}{l}\text { Tidak } \\
\text { multikolineritas }\end{array}$ & terjadi \\
\hline $\begin{array}{l}\text { Positioni } \\
\text { ng } \\
\text { produk }\end{array}$ & 0,498 & 2,008 & $\begin{array}{l}\text { Tidak } \\
\text { multikolineritas }\end{array}$ & terjadi \\
\hline Lifestyle & 0,378 & 2,643 & $\begin{array}{l}\text { Tidak } \\
\text { multikolineritas }\end{array}$ & terjadi \\
\hline
\end{tabular}

Factor(VIP).Apabila nilai tolerance $>10 \%$ dan nilai $\mathrm{VIF} \leq 10$, maka hasil penelitian dapat disimpulkan tidak ada multikolineritas antar variabel bebas.

Dari tabel diatas maka dapat diketahui bahwa variabel kualitas Citra merek, Positioning produk, dan Lifestyle tidak terjadi multikolinearitas.

c. Uji heteroskedastisitas

bertujuan untuk menguji apakah dalam regresi terjadi ketidaksamaan variance dari residual satu pengamatanke pengamatan.Pengujian heteroskedastisitas dapat dilakukan dengan uji glejser dengan cara meregres nilai absolute residual terhadap variabel independen.Jika $\mathrm{P}_{\text {value }}>0,05$ maka tidak terjadi heteroskedastisitas dan jika $\mathrm{P}_{\text {value }} \leq 0,05$ maka terjadi heteroskedastisitas.

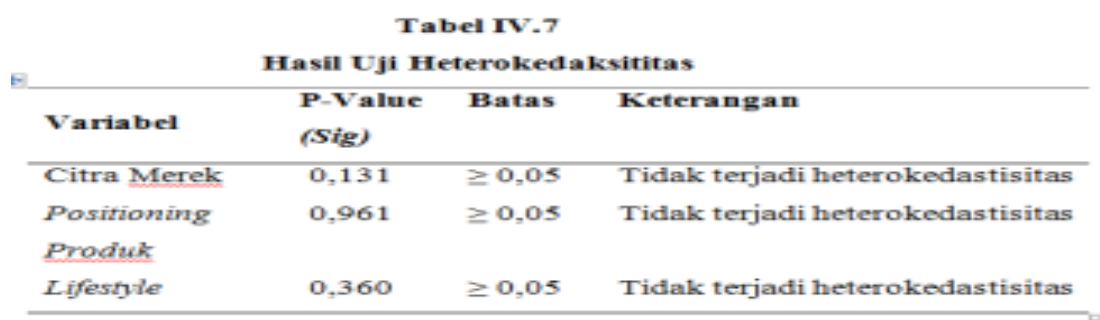


Dari tabel diatas maka dapat diketahui bahwa Citra Merek, Positioning Produk, dan Lifestyle tidak terjadi heteroskedastis

\section{2) Uji Regresi Linier Berganda}

Persamaan regresi dalam penelitian ini adalah untuk mengetahui seberapa besar pengaruh variabel independencitra merek $\left(\mathrm{X}_{1}\right)$, positioning produk $\left(\mathrm{X}_{2}\right)$, danlifestyle $\left(\mathrm{X}_{3}\right)$ terhadap keputusan pembelian (Y).Hasil dari uji regresi linier berganda dapat dijelaskan pada tabel dibawah ini :

Tabel : IV.8

Hasil Pengujian Regresi Linier Berganda

\begin{tabular}{|c|c|l|l|l|l|}
\hline Variabel & \multicolumn{1}{|c|}{ B } & Beta & t hitung & Sig.t & Ket \\
\hline ( constant ) & 3,607 & & & & Signifikan \\
\hline Citra merek & 0,204 & 2,791 &, 006 &, 003 & Signifikan \\
\hline $\begin{array}{c}\text { Positioning } \\
\text { produk }\end{array}$ & 0,191 & 2,744 &, 007 &, 006 & Signifikan \\
\hline Lifestyle & 0,365 & 4,109 &, 000 &, 007 & \\
\hline $\begin{array}{c}\text { F hitung } \\
\text { Sig f }\end{array}$ & $\begin{array}{c}\mathbf{5 7 , 6 9 9} \\
\mathbf{0 , 0 0 0}\end{array}$ & & & & \\
\hline R square & $\mathbf{0 , 6 4 3}$ & & & & \\
\hline $\begin{array}{c}\text { Varibel } \\
\text { dependen }\end{array}$ & & $\begin{array}{c}\text { Keputusan } \\
\text { pembelian }\end{array}$ & & & \\
\hline
\end{tabular}

Berdasarkan hasil analisis regresi linier berganda diperoleh persamaan garis regresinya sebagai berikut :

Keterangannya ;

Didapatkannya nilai konstanta 3,607 Variabel Citra $\operatorname{Merek}\left(\mathrm{X}_{1}\right)$, Positioning Produk $\left(\mathrm{X}_{2}\right)$ dan Lifestyle $\left(\mathrm{X}_{3}\right)$ mempunyai arah koefisien yang bertanda positif

$$
\mathrm{Y}=3,607+0,204 \mathrm{X}_{1}+0,191 \mathrm{X}_{2}+0,365 \mathrm{X}_{3}
$$

a. terhadap keputusan pembelian (Y) dengan nilai sebesar 3,607.

b. Koefesien Citra Merek memberikan nilai positif yang berarti bahwa jika Citra Mereksemakin baik dengan asumsi variabel lain tetap maka keputusan pembelian akan mengalami peningkatan sebesar 0,204.

c. Koefisien Positioningproduk memberikan nilai positif yang berarti bahwa jika positioning produk semakin kuat dengan asumsi variabel lain tetap maka keputusan pembelian akan mengalami peningkatan sebesar 0,191.

d. Koefisien Lifestyle memberikan nilai positif yang berarti bahwa jika perusahaan membuat produk yang sesuai dengan kebutuhan masyarakat dengan asumsi variabel lain tetap maka keputusan pembelian akan mengalami peningkatan sebesar 0,365. 


\section{3) Uji Hipotesis}

a. Uji F

Pengujian ini digunakan untuk mengetaahui signifikan pengaruh variable citra merek(X1), Positioning produk (X2), dan lifestyle (X3) secara bersama-sama terhadap keputusan pembelian (Y).hasil uji F pada tabel III

Nilai $F$ hitung $>$ F tabel $(57,699)>(2,70)$ dengan signifikan $0,000 \leq 0,05$ maka dapat disimpulkan $\mathrm{H}_{\mathrm{O}}$ ditolak artinya variabel citra merek,Positioning produk dan lifestylesecara simultan dan signifikan berpengaruh terhadap keputusan pembelian The Executive di solo paragon mall.

b. Uji t

Uji $\mathrm{t}$ digunakan untuk menguji signifikan secara parsial pengaruh variabel independen yang terdiri dari citra merek $\left(\mathrm{X}_{1}\right)$, positioning produk $\left(\mathrm{X}_{2}\right)$ dan lifestyle $\left(\mathrm{X}_{3}\right)$ terhadap variabel dependen yaitu keputusan pembelian $(\mathrm{Y})$.Berdasarkani hasili analisis penelitian pada Tabel III dapati disimpulkansebagaii berikut :

1) Pada variabel citra merek hasil nilai $t$ hitung $(3,694)>t$ tabel $(1,984)$ dengan signifikan $0,000 \leq 0.05$ artinya $\mathrm{H}_{0}$ ditolak, secara parsial citra merek memiliki pengaruh positif dan signifikan terhadap keputusan pembelian The Executive di solo paragon mall.

2) Pada variabel positioning produk $\left(X_{2}\right)$ hasil nilai $t_{\text {hitung }}(2,744)>t_{\text {tabel }}(1,984)$ dengan signifikan $0,006 \leq 0.05$ artinya $\mathrm{H}_{0}$ ditolak, secara parsial positioning

3) produk $\left(\mathrm{X}_{2}\right)$ memiliki pengaruh positif dan signifikan terhadap keputusan pembelian The Executive di solo paragon mall.

4) Pada variabel Lifestyle $\left(X_{3}\right)$ hasil nilai $t$ hitung $(4,109)>t$ tabel $(1,984)$ dengan signifikan $0,000 \leq 0.05$ artinya $\mathrm{H}_{0}$ ditolak, secara parsial Lifestyle $\left(\mathrm{X}_{3}\right)$ memiliki pengaruh positif dan signifikan terhadap keputusan pembelian The Executive disolo paragon mall.

\section{c. Koefisien Determinasi}

Koefisien determinasi pada intinya untuk mengukur seberapa jauh variabel bebas dalam menerangkan variabel terikat. Hasil dari perhitungan analisis regresi linear berganda dapat diketahui bahwa besarnya koefisien detrminasi (Adjusted $R^{2}$ ) yang diperoleh 0,632 atau 63,2\%. Hal ini menunjukkan bahwa 63,2\% keputusan pembelian The Executive di solo paragon malldipengaruhi oleh variabel independen berupa variabel Citra Merek, Variabel Positioning Porduk dan variabel Lifestyle. Sedangkan sisanya sebesar 36,8\% dipengaruhi oleh variabel lain diluar dari variabel penelitian.

\section{PEMBAHASAN}

1) Hasil penelitian menunjukan variabel citra $\operatorname{merek}\left(X_{1}\right)$ diperoleh nilai $t$ hitung 2,791 dengan nilai signifikan 0,000 dan koefisien regresi mempunyai nilai positif sebesar 0,256 berdasarkan hasil tersebut diperoleh keterangan bahwa variabel citra merek berpengaruh positif terhadap keputusan pembelian The Executive disolo paragon mall secara signifikan.Penelitian ini mendukung penelitian yang dilakukan oleh evelina dkk(2012) menyatakan bahwa citra merek berpengaruh secara positif dan signifikan terhadap keputusan pembelian.

2) Hasil penelitian menunjukkan variabel positioning produk $\left(\mathrm{X}_{2}\right)$ diperoleh nilai $t$ hitung 2,744 dengan nilai signifikan ,007 dan koefisien regresi mempunyai nilai positif sebesar 0,191 berdasarkan hasil tersebut diperoleh keterangan bahwa variabel positioning produk 
berpengaruh positif terhadap keputusan pembelian The Executivedi solo paragon mall secara signifikan. Konsumen cenderung menilai suatu produk dari kualitas, harga, promosi dan tempat. Strategi bauran pemasaran yang dirancang oleh perusahaan merupakan faktor penentu tingkat kepuasan yang diperoleh dari konsumen setelah melakukan pembelian. Penelitian ini sejalan dengan penelitian yang dilakukan Rahmawati dan Arsyanto (2018) menyatakan Positioning Produk memiliki pengaruh positif dan signifikan terhadap keputusan pembelian.

3) Hasil penelitian menunjukkan variabel lifestyle $\left(\mathrm{X}_{3}\right)$ diperoleh nilai thitung 4,109 dengan nilai signifikan 0,000 dan koefisien regresi mempunyai nilai positif sebesar 0,365 berdasarkan hasil tersebut diperoleh keterangan bahwa variabel lifestyle berpengaruh positif terhadap keputusan pembelian The Executive di solo paragon mall secara signifikan. Penelitian ini sejalan dengan penelitian Sisilia Oktavia (2015) dan Ujang Setiawan (2015) kedua penelitian tersebut menyatakan lifestyle ada pengaruh positif dan signifikan terhadap keputusan pembelian.

\section{KESIMPULAN}

Kesimpulan dari penelitian Citra Merek, Positioning Produk dan Lifestyle terhadap keputusan pembelian pada toko baju the executive di Solo paragon mall adalah sebagai berikut :

a. Variabel Citra merek secara parsial berpengaruh positif dan signifikan terhadap keputusan pembelian pada toko baju the executive disolo paragon mall. Artinya semakin di kenal citra merek dari The Executive dengan banyaknya pilihan produk, dan inovasi produk yang di tawarkan The Executive.

b. Variabel Positioning produk secara parsial berpengaruh positif dan signifikan terhadap keputusan pembelian produk The Executive artinya semakin bagus konsep bauran pemasaran yang dirancang perusahaan maka semakin meningkat pula konsumen yang melakukan pembelian

c. Variabel Lifestyle secara parsial berpengaruh positif dan signifikan terhadap keputusan pembelian produk The Executive. Dijelaskan variabel lifestyle lebih berpengaruh signifikan terhadap keputusan pembelian produk The Executive di solo paragon mall.

d. Hasil uji F menunjukan bahwa variabel Citra merek, Positioning produk dan Lifestyle secara simultan dan signifikan memberikan pengaruh yang positif terhadap keputusan pembelian.

e. Berdasarkan hasil Analisis koefisien determinasi diperoleh nilai sebesar 0,802 Yang berarti keputusan keputusan pembelian The Executive dipengaruhi oleh variabel independen berupa variabel citra merek, variabel positioning produk, dan variabel lifestyle sebesar $80,2 \%$, sedangkan sisanya sebesar $36.8 \%$ dipengaruhi oleh variabel lain diluar dari variabel penelitian.

\section{SARAN}

Berdasarkan simpulan dan pembahasan hasil penelitian, maka saran yang untuk dapat dijadikan pertimbangan adalah sebagai berikut:

a. Perusahaan harus mempertahanan bahkan meningkatkan image yang terbentuk dalam produk The Executive, misalnya dengan menambah inovasi produk perlu disadari bahwa mempertahankan pelanggan jauh lebih baik serta menguntungkan dibanding mencari konsumen baru untuk dijadikan pelanggan.

b. Perusahaan harus mampu membuat konsep bauran pemasaran yang lebih baik lagi, misalnya dari segi promosi. Menambah wawasan tentang product knowledge untuk salles assistant sangat berpengaruh dalam terjadinya keputusan pembelian konsumen. 
Dimana saat terjadinya selling, sales assistant mampu dan cakap melakukan story telling, baik dari segi kualitas bahan, dan mix $n$ match produk yang ada di The Executive.

\section{DAFTAR PUSTAKA}

Umboh, Oktavia Sisilia Dkk, 2015. “ Analisis Kualitas Produk, Brand Image, dan Lifestyle Terhadap Keputusan Pembelian Pakaian Di Missisipi Manado Town Square”. Jurnal Emba. Vol.3.No.1.

Setiawan, Ujang, Dkk. 2015.“ Pengaruh Citra Merek, Harga, Kualitas Produk Dan Gaya Hidup Terhadap Keputusan Pembelian Handpone Blackberry Gemini”. Jurnal Of Management. Vol. 1.No.1

Arsyanto, Tody Muhhamad dan Rahmawati. 2018. “Anilisis Pengaruh Positioning Produk, Dan Citra Merek Terhadap Keputusan Pembelian”. Jurnal Inovasi Bisnis Dan Manajemen Indonesia.Vol.2.No.1.

Malik, Djamaludin. Dkk.2018. “Pengaruh Harga, Promosi, Dan Kualitas Produk Terhadap Keputusan Pembelian Produk Torabika”. Journal Off Management. Vol.4.No.4 